\title{
Ameliorative effects of ceftriaxone sodium combined with dexamethasone on infantile purulent meningitis and associated effects on brain-derived neurotrophic factor levels
}

\author{
YIWEN ZENG and WEI ZHANG \\ Department of Pediatrics, Yongchuan Hospital of Chongqing Medical University, \\ Yongchuan, Chongqing 402160, P.R. China
}

Received October 11, 2018; Accepted January 9, 2020

DOI: $10.3892 /$ etm.2020.8769

\begin{abstract}
The aim of the present study was to evaluate the role of ceftriaxone sodium combined with dexamethasone on the treatment of infant purulent meningitis (PM) and to measure brain-derived neurotrophic factor (BDNF) levels in children with PM. Of the 177 patients enrolled into the present study, 92 patients received ceftriaxone sodium+dexamethasone (combination group) and 85 patients received ceftriaxone sodium alone (monotherapy group). The time taken for the body temperature, peripheral blood (PB) and cerebrospinal fluid (CSF) white blood cell (WBC) counts to recover back to normal levels were compared between the two groups. In addition, changes in the CSF WBC counts, CSF protein and sugar concentrations, BDNF levels, effective treatment rates and incidence of adverse reactions three days before treatment (T1), after one week of treatment (T2) and after two weeks of treatment (T3) were compared between the two groups. In the combination group, the recovery time of body temperature, WBC counts in both $\mathrm{PB}$ and CSF were significantly lower compared with those in the monotherapy group. The combination group also exhibited lower CSF protein concentrations and higher CSF sugar concentrations at T2 and T3 compared with those in the monotherapy group $(\mathrm{P}<0.05)$. The effective treatment rate of the combination group was significantly higher compared with that of the monotherapy group $(\mathrm{P}=0.006)$. CSF protein at $\mathrm{T} 1, \mathrm{~T} 2 \mathrm{~T} 3$, and CSF sugar concentrations and BDNF levels at $\mathrm{T} 1$ were significantly lower in the combination group than in the monotherapy group $(\mathrm{P}<0.05)$ while the CSF sugar concentrations at T2, T3 were higher in the combination group than in the monotherapy group $(\mathrm{P}<0.05)$. Taken together, these observations suggest
\end{abstract}

Correspondence to: Dr Wei Zhang, Department of Pediatrics, Yongchuan Hospital of Chongqing Medical University, 439 Xuanhua Road, Yongchuan, Chongqing 402160, P.R. China

E-mail: weihelloz@163.com

Key words: ceftriaxone sodium, dexamethasone, purulent meningitis, brain-derived neurotrophic factor that ceftriaxone combined with dexamethasone was superior compared with that of ceftriaxone alone for the treatment of infantile PM, and that this combination therapy may improve the effective treatment rate and accelerate patient rehabilitation.

\section{Introduction}

Purulent meningitis (PM), caused by pyogenic bacteria, is common in children aged $\leq 5$ years (1). The incidence of PM in children is increasing, with the number of new cases of infantile PM globally exceeding 300,000 as of 2015 (2). Additionally, it was previously reported that the incidence of PM is exhibiting major geographical differences, with higher rates of incidence observed in developing countries (3). Infants are particularly vulnerable to a variety of PM-causing pyogenic bacterial infections, the most common species being Neisseria meningitidis., Streptococcus pneumoniae and Haemophilus influenzae (4). Since acute infant PM is severe and harmful, missing the optimal treatment time directly endangers the life of the patients (5); if not treated on time, the mortality rate associated with this disease can reach $50-70 \%$ (6).

Accumulating evidence has demonstrated that the optimal treatment strategy for PM is antibiotic therapy (7). However, in recent years, novel pharmacological agents for the effective treatment of PM such as ceftriaxone have been developed with advancing technology (8). The antibacterial spectrum of ceftriaxone sodium is comparable to that of cefotaxime sodium, which it has potent effects against Escherichia coli, Klebsiella pneumoniae, Proteus mirabilis, Serratia, Meningococcus and Neisseria gonorrhoeae (9). Although it has been demonstrated in a number of previous studies to be highly effective for the treatment of infant PM (10-12), the efficacy of ceftriaxone sodium in infantile PM is deteriorating due to a surge of bacterial resistance in the population (13). Dexamethasone is a synthetic corticosteroid which exhibits anti-inflammatory properties and that is considered safe in pregnant women and newborns $(14,15)$. Previous studies have shown that the additive use of dexamethasone can greatly enhance the efficacy of antibiotics $(16,17)$. At present, limited information exist on the efficacy of ceftriaxone sodium combined with dexamethasone on the treatment of infant PM. The present study retrospectively analyzed the role 
of ceftriaxone sodium combined with dexamethasone for the treatment of infant PM at the Department of Pediatrics, Yongchuan Hospital of Chongqing Medical University (Chongqing, China) and its associated effects on brain-derived neurotrophic factor (BDNF) levels. The study provides an effective reference and guidance for future clinical management of PM.

\section{Patients and methods}

Patients. A retrospective analysis was performed on 177 children (sex, 114 males and 63 females; age range, between 5 months and 6 years; mean age, 3.27 \pm 1.42 years) who were admitted to Yongchuan Hospital of Chongqing Medical University (Chongqing, China) between January 2015 and February 2016. The present study was approved by the Ethics Committee of Yongchuan Hospital of Chongqing Medical University (Chongqing, China) and informed consent was obtained from the parents of all subjects.

The inclusion criteria were: i) Age of patient $<8$ years; ii) Early symptoms of meningitis, including nausea and vomiting; fever; headache and a stiff neck; muscle pain; sensitivity to light; confusion; cold hands or feet and mottled skin; in some cases, subjects had a rash that did not fade under pressure. Later symptoms included seizures and coma. iii) diagnosed with PM with severity evaluated following cerebrospinal fluid (CSF) and CT examination at the hospital using the diagnostic criteria of the 2015 PM Diagnostic Guidelines (14); iv) was receiving follow-up treatment in our hospital after diagnosis; v) cooperation with hospital staff; and vi) having complete set of medical records.

The exclusion criteria were: i) Patients with cancer, diseases of the immune system, blood or severe organ disorders, hepatocellular failure or renal failure, other infectious diseases and drug allergies; ii) patients who received medical treatments other than prescribed drugs from our hospital following diagnosis; and iii) patients who were transferred from other hospitals.

Methods. Following explanation of the mechanism of action and effects of ceftriaxone sodium and dexamethasone, the families of the respective patients selected the treatment regimens independently. Of the 177 patients enrolled into the present study, 92 were treated with ceftriaxone sodium combined with dexamethasone, which served as the combination group; the other 85 patients who received ceftriaxone sodium treatment only served as the monotherapy group. The treatment regimens performed in the present study were determined in accordance with the bacterial species found. For any cases of unidentified pathogenic bacterial suppurative meningitis, third-generation ceftriaxone or cefotaxime was used as the first choice of treatment, whilst for pneumococcal disease, high-dose penicillin was used. For those who were resistant to penicillin, ceftriaxone was considered in addition to vancomycin. For meningococcal infection, penicillin was preferred, whereas those who were penicillin-resistant were treated with cefotaxime or ceftriaxone. Ceftazidime was used for meningitis caused by Pseudomonas aeruginosa, whilst ceftriaxone, cefotaxime or ceftazidime was used for other forms of meningitis caused by gram-negative bacilli.
The monotherapy group was administered $\sim 70-90 \mathrm{mg} / \mathrm{kg}$ ceftriaxone sodium once daily (Southwest Pharmaceutical Co., Ltd.), whereas the combination group was administered additively with $0.3 \mathrm{mg} / \mathrm{kg}$ dexamethasone once daily (Guizhou Tiandi Pharmaceutical Co., Ltd.). Both groups of treatment regimens lasted for two weeks, which would be stopped immediately if any patient developed an adverse reaction. The recovery of a set of PM indicators to normal healthy levels was considered as the completion of treatment. CSF samples $(3 \mathrm{ml})$ were obtained within three days prior to treatment (T1), at one week after treatment (T2) and two weeks after treatment (T3) for further analysis. After centrifugation at 1,500 x $\mathrm{g}$ for $5 \mathrm{~min}$ at $4^{\circ} \mathrm{C}$, the supernatant was taken for subsequent testing.

Outcome indicators. Clinical data from the two groups of children, including age, course of disease, weight, red blood cell (RBC) count, white blood cell (WBC) count, platelet count, sex, place of residence and first onset of symptoms were compared. The rehabilitation indicators measured were time taken for the recovery of body temperature and WBC counts in both the peripheral blood (PB) and CSF returning to normal, healthy levels. The CSF biochemical indicators included WBC count, concentration of protein and sugar in the CSF and BDNF levels. BDNF levels in the CSF were analyzed using an ELISA kit (Shanghai Yubo Biological Technology Co., Ltd.; cat. no. KT11531), whilst the biochemical parameters in CSF were determined using an automatic biochemical analyzer (AU5800; Beckman Coulter, Inc.).

Effective rate. The effective treatment rates were determined using the evaluation criteria referred to as the 2015 PM Rehabilitation Guidelines (14). Clinical symptoms and normal CSF examination findings were defined as 'effective'; normalized clinical symptoms and CSF examination findings or results indicating significant improvement were defined 'improved'; and clinical symptoms and CSF examination findings revealing uniformity or even deterioration were defined as 'ineffective.' The effective treatment rate was calculated using the following formula: [('Effective' + 'Improved')/total number of cases] $\times 100 \%$. The incidence of adverse reactions was using the following formula: (Number of patients with adverse reactions during treatment/total number of cases) $\mathrm{x} 100 \%$.

Statistical analysis. The data were analyzed using SPSS version 24.0 (IBM Corp.). Categorical variables and effective treatment rates between the two groups were compared using the Chi-square test. Continuous variables, including the recovery time of body temperature and WBC counts, were presented as the mean \pm standard deviation and compared between the two groups using Student's t-test. Multiple time points were compared using repeated measures ANOVA followed by Bonferroni test. $\mathrm{P}<0.05$ was considered to indicate a statistically significant difference. The experiments were repeated 3 times.

\section{Results}

General data and rehabilitation outcomes. There were no significant differences in age, gender, body weight, location 
Table I. General characteristics of patients.

\begin{tabular}{|c|c|c|c|c|}
\hline Characteristic & Combination $(\mathrm{n}=92)$ & Monotherapy $(n=85)$ & $\mathrm{X}^{2}$ or $\mathrm{t}$ & P-value \\
\hline Age & $3.42 \pm 1.67$ & $3.18 \pm 1.84$ & 0.91 & 0.36 \\
\hline Course of disease (days) & $5.23 \pm 1.04$ & $5.51 \pm 1.22$ & 1.647 & 0.1 \\
\hline Body weight (kg) & $16.63 \pm 5.27$ & $17.52 \pm 6.04$ & 1.047 & 0.3 \\
\hline $\mathrm{RBC}\left(\mathrm{x} 10^{12} / 1\right)$ & $4.12 \pm 0.84$ & $4.09 \pm 1.15$ & 0.199 & 0.84 \\
\hline WBC (x109/1) & $47.24 \pm 7.68$ & $45.81 \pm 8.54$ & 1.173 & 0.24 \\
\hline $\operatorname{PLT}\left(\times 10^{9} / 1\right)$ & $247.52 \pm 24.16$ & $241.34 \pm 26.54$ & 1.622 & 0.11 \\
\hline Total bilirubin at $\mathrm{T} 1(\mu \mathrm{mol} / \mathrm{l})$ & $16.72 \pm 2.51$ & $17.21 \pm 2.66$ & 1.261 & 0.21 \\
\hline Total bilirubin at T3 $(\mu \mathrm{mol} / \mathrm{l})$ & $15.62 \pm 2.16$ & $15.16 \pm 2.38$ & 1.348 & 0.18 \\
\hline BUN at T1 & $5.65 \pm 2.06$ & $5.87 \pm 2.05$ & 0.712 & 0.48 \\
\hline BUN at T3 & $5.12 \pm 1.04$ & $5.25 \pm 1.27$ & 0.747 & 0.46 \\
\hline \multicolumn{5}{|l|}{ Sex } \\
\hline Male & $62(67.39)$ & $52(61.18)$ & & \\
\hline Female & $30(32.61)$ & $33(38.82)$ & & \\
\hline Place of residence & & & 0.689 & 0.41 \\
\hline Town & $69(75.00)$ & $59(69.41)$ & & \\
\hline Rural & $23(25.00)$ & $26(30.59)$ & & \\
\hline Only Child & & & 0.431 & 0.51 \\
\hline Yes & $50(54.35)$ & $42(49.41)$ & & \\
\hline No & $42(45.65)$ & $43(50.59)$ & & \\
\hline First onset & & & 1.221 & 0.27 \\
\hline Yes & $81(88.04)$ & 79 (92.94) & & \\
\hline No & $11(11.96)$ & $6(7.06)$ & & \\
\hline Pathogen species & & & 0.701 & 0.7 \\
\hline Meningococcus & $38(41.30)$ & $32(37.65)$ & & \\
\hline Gram-negative bacilli & $30(32.61)$ & $26(30.59)$ & & \\
\hline Pneuтососсиs & $24(26.09)$ & 27 (31.76) & & \\
\hline Family medical history & & & 0.255 & 0.61 \\
\hline Yes & $12(13.04)$ & $9(10.59)$ & & \\
\hline No & $80(86.96)$ & $76(89.41)$ & & \\
\hline Severity of disease & & & 0.099 & 0.95 \\
\hline Ordinary type & $47(51.09)$ & $44(51.76)$ & & \\
\hline Sudden & $19(20.65)$ & $16(18.82)$ & & \\
\hline Light & $26(28.26)$ & $25(29.41)$ & & \\
\hline
\end{tabular}

Categorical variables, are presented as $\mathrm{n},(\%)$. Continuous variables are presented as the mean $\pm \mathrm{SD}$. RBC, red blood cell; WBC, white blood cell; PLT, platelets; BUN, blood urea nitrogen.

of residence, total bilirubin levels, BUN, number of siblings, family medical history, course of disease, species of pathogens, severity of disease, red blood cell (RBC), WBC and platelet (PLT) counts in routine blood examinations between the two groups, suggesting that the two groups were comparable prior to treatment (Table I).

The recovery time of body temperature in the combination group was $2.87 \pm 0.74$ days, which was significantly shorter compared with that in the monotherapy group (3.67 \pm 0.94 days; $\mathrm{P}<0.05$; Fig. 1). The recovery time of the PB WBC count in the combination group was 5.57 \pm 2.07 , which was significantly shorter compared with that in the monotherapy group $(8.04 \pm 1.68$ days; $\mathrm{P}<0.05$; Fig. 2$)$. The recovery time for CSF WBC count to normal level in the combination group was $14.14 \pm 1.24$ days, which was also significantly shorter compared with that in the monotherapy group (17.84 \pm 2.07 days; $\mathrm{P}<0.05$; Fig. 3).

Comparison of the CSF biochemical parameters. No significant differences were observed in the WBC count (Fig. 4), CSF protein (Fig. 5) and sugar concentrations (Fig. 6) between the combination and the monotherapy groups at $\mathrm{T} 1$. At T2, the WBC count $\left(62.87 \pm 10.54 \times 10^{6} / 1\right)$ and CSF protein concentration $(0.61 \pm 0.10 \mathrm{~g} / \mathrm{l})$ in the combination group were significantly lower (both $\mathrm{P}<0.05$ ) compared with those in the monotherapy group (WBC count, $75.24 \pm 12.84 \times 10^{6} / 1$; CSF 


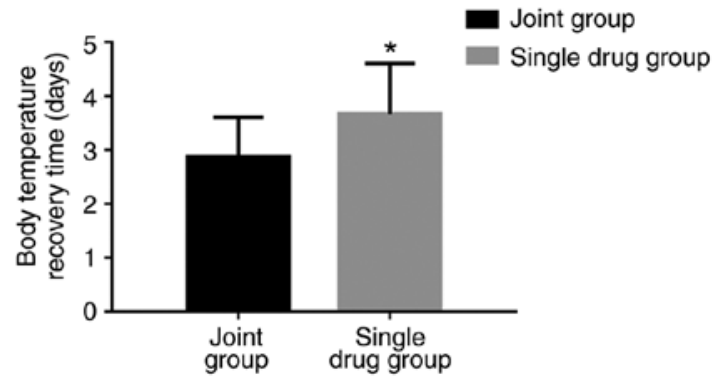

Figure 1. Comparison of body temperature recovery times between the two therapy groups. The recovery time of body temperature in the monotherapy group was significantly longer compared with that in the combination group. ${ }^{*} \mathrm{P}<0.05$ vs. combination.

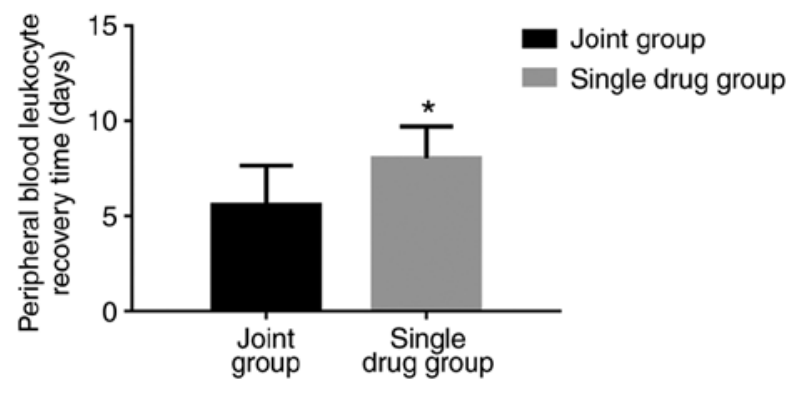

Figure 2. Comparison of peripheral blood WBC count recovery times between the two therapy groups. The recovery time of peripheral blood WBCs in the monotherapy group was significantly longer compared with that in the combination group. ${ }^{*} \mathrm{P}<0.05$ vs. combination. WBC, white blood cell.

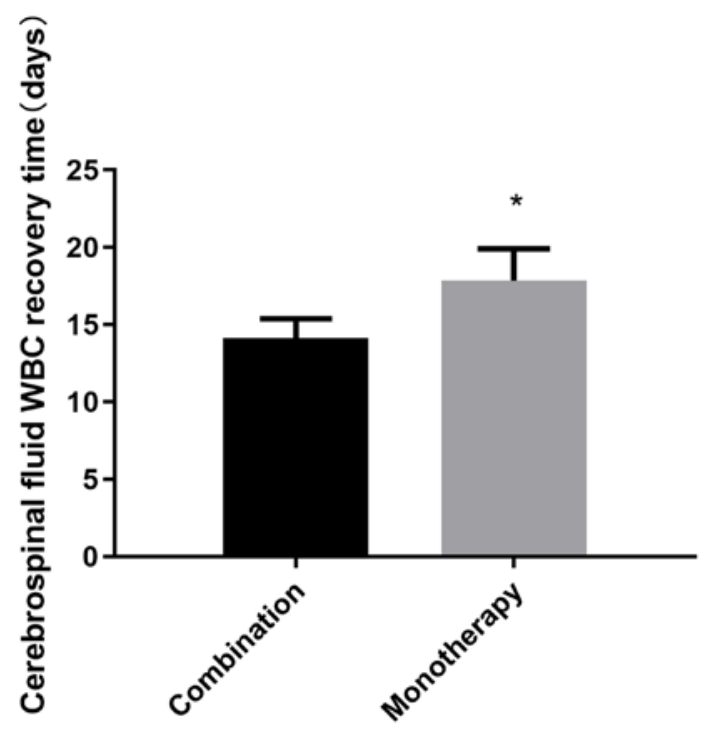

Figure 3. Comparison of the cerebrospinal fluid WBC count recovery times between the two therapy groups. The recovery time of peripheral blood WBC count in the monotherapy group was significantly longer compared with that in the combination group. ${ }^{*}<<0.05$ vs. combination. WBC, white blood cell.

protein concentration, $0.81 \pm 0.14 \mathrm{~g} / \mathrm{l})$. The CSF sugar concentration in the combination group was $2.57 \pm 0.61 \mathrm{mmol} / 1$, which was significantly higher compared with that in the monotherapy group $(1.47 \pm 0.54 \mathrm{mmol} / \mathrm{l} ; \mathrm{P}<0.05)$ at $\mathrm{T} 2$. At $\mathrm{T} 3$, the WBC count and CSF protein concentration in the combination group were $34.71 \pm 8.68 \times 10^{6} / 1$ and $0.37 \pm 0.08 \mathrm{~g} / 1$,

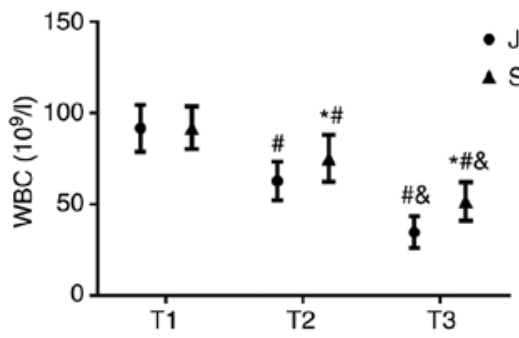

Figure 4. CSF WBC counts between the combination and monotherapy groups during treatment as measured at three different time points. At both $\mathrm{T} 2$ and T3, the CSF WBC counts in the monotherapy group were significantly higher compared with those in the combination group. In both groups, the WBC count was lower at T3 compared with T2, which were in turn lower compared with $\mathrm{T} 1 .{ }^{*} \mathrm{P}<0.05$ vs. combination; ${ }^{\#} \mathrm{P}<0.05$ vs. corresponding value at $\mathrm{T} 1$ and ${ }^{\circledR} \mathrm{P}<0.05$ vs. corresponding value at $\mathrm{T} 2$. WBC, white blood cell; CSF, cerebrospinal fluid; T1, before treatment; T2, one week after treatment; T3, two weeks after treatment.

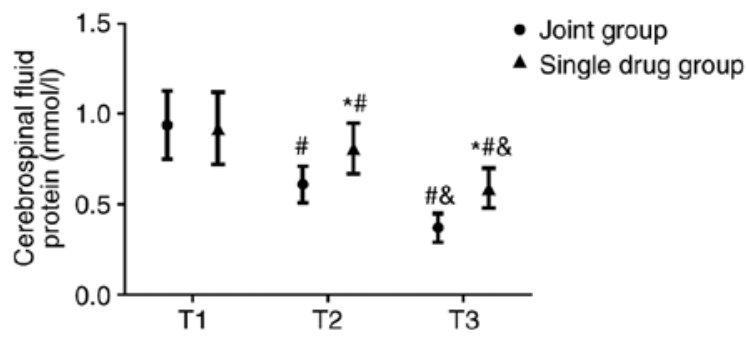

Figure 5. CSF protein concentrations between the combination and monotherapy groups during treatment as measured at three different time points. The CSF protein concentrations in the monotherapy group was significantly higher compared that of the combination group at both T2 and T3, In both groups, the CSF protein concentrations were lower at $\mathrm{T} 3$ compared with $\mathrm{T} 2$, which were in turn lower compared with $\mathrm{T} 1 .{ }^{*} \mathrm{P}<0.05$ vs. combination; ${ }^{\text {}} \mathrm{P}<0.05$ vs. corresponding value at $\mathrm{T} 1$ and ${ }^{\circledR} \mathrm{P}<0.05$ vs. corresponding value at T2. CSF, cerebrospinal fluid; T1, before treatment; T2, one week after treatment; T3, two weeks after treatment.

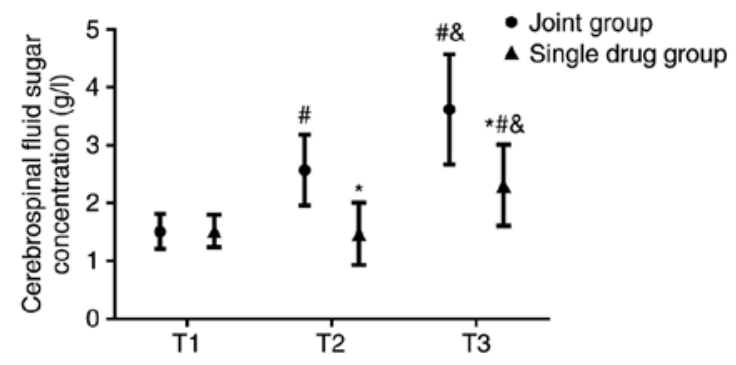

Figure 6. CSF sugar concentrations between the combination and monotherapy groups during treatment as measured at three different time points. At both T2 and T3, CSF sugar concentrations were significantly lower in the monotherapy group compared with the combination group. In the combination group, the CSF sugar concentrations were significantly higher at T3 compared with at $\mathrm{T} 2$, which were in turn higher compared with those at $\mathrm{T} 1$. ${ }^{*} \mathrm{P}<0.05$ vs. combination; ${ }^{\text {}} \mathrm{P}<0.05$ vs. corresponding value at $\mathrm{T} 1$ and ${ }^{\circledR} \mathrm{P}<0.05$ vs. corresponding value at $\mathrm{T} 2$. CSF, cerebrospinal fluid; $\mathrm{T} 1$, before treatment; $\mathrm{T} 2$, one week after treatment; $\mathrm{T} 3$, two weeks after treatment.

respectively, both of which were also significantly lower (both $\mathrm{P}<0.05)$ compared with those in the monotherapy group (WBC count, $51.63 \pm 10.54 \times 10^{6} / 1$; CSF protein concentration, $0.59 \pm 0.11 \mathrm{~g} / \mathrm{l})$. The CSF sugar concentration in the combination group was $3.62 \pm 0.95 \mathrm{mmol} / \mathrm{l}$, which was also 
Table II. Comparison of treatment effectiveness.

\begin{tabular}{|c|c|c|c|c|}
\hline Outcome & Combination group $(n=92)$ & Monotherapy group $(n=85)$ & $X^{2}$ & P-value \\
\hline Effective [n (\%)] & $57(61.96)$ & $32(37.65)$ & & \\
\hline Improved [n (\%)] & $30(32.61)$ & $33(38.82)$ & & \\
\hline Ineffective [n (\%)] & $5(5.43)$ & $20(23.53)$ & & \\
\hline Effective treatment rate $(\%)$ & $94.57 \%$ & $76.47 \%$ & 11.930 & 0.006 \\
\hline
\end{tabular}

Table III. Comparison of incidence of adverse reactions.

\begin{tabular}{|c|c|c|c|c|}
\hline Adverse reaction & Combination group $(n=92)$ & Monotherapy group $(n=85)$ & $X^{2}$ & P-value \\
\hline $\operatorname{Rash}[\mathrm{n}(\%)]$ & $0(0.00)$ & $1(1.18)$ & 1.089 & 0.297 \\
\hline Jaundice $[\mathrm{n}(\%)]$ & $2(2.17)$ & $2(2.35)$ & 0.006 & 0.936 \\
\hline Flatulence [n (\%)] & $1(1.09)$ & $0(0.00)$ & 0.929 & 0.335 \\
\hline Diarrhea [n (\%)] & $3(3.26)$ & $4(4.71)$ & 0.243 & 0.622 \\
\hline Adverse reaction rate $(\%)$ & $5.43 \%$ & $8.24 \%$ & 0.548 & 0.459 \\
\hline
\end{tabular}

significantly higher compared with that in the monotherapy group $(2.31 \pm 0.70 \mathrm{mmol} / \mathrm{l} ; \mathrm{P}<0.05)$.

The WBC count and CSF protein concentrations in both groups were lower at $\mathrm{T} 2$ compared with those at $\mathrm{T} 1(\mathrm{P}<0.05)$, which decreased further at $\mathrm{T} 3(\mathrm{P}<0.05)$. By contrast, the CSF sugar concentration of the combination group increased at $\mathrm{T} 2$ compared with $\mathrm{T} 1(\mathrm{P}<0.050)$, which increased further at T3 $(\mathrm{P}<0.05)$. No significant differences in the CSF sugar concentration could be identified between $\mathrm{T} 1$ and $\mathrm{T} 2$ in the monotherapy group, although it was higher at T3 compared with T1 ( $\mathrm{P}<0.05$; Figs. 4-6).

Comparison of effective treatment rates and adverse reactions. The effective treatment rate for the combination group was calculated to be $94.57 \%$, which was significantly higher compared with that of the monotherapy group (76.47\%; $\mathrm{P}=0.006$; Table II). In the combination group, the patients were primarily 'effective' to the treatment, accounting for $61.96 \%$, whilst in the monotherapy group, a slight majority of the patients were categorized as 'improved' $(38.82 \%)$. The incidence of adverse reactions in the combination group was calculated to be $5.43 \%$, which was not significantly different compared with the monotherapy group (Table III).

Comparison of BDNF levels. There was no significant difference in the BDNF levels between the two groups at T1 (Fig. 7). The BDNF levels in the combination group at $\mathrm{T} 2$ was $12.84 \pm 6.24$, which was significantly higher compared with that in the monotherapy group $(8.67 \pm 3.65 ; \mathrm{P}<0.05$; Fig. 7). The BDNF levels in the combination group at T3 was $27.52 \pm 5.61$, which was also significantly higher compared with that in the monotherapy group $(16.84 \pm 5.99 ; \mathrm{P}<0.05$; Fig. 7).

The BDNF levels in both groups were significantly increased at $\mathrm{T} 2(\mathrm{P}<0.05)$ which increased further at $\mathrm{T} 3$ ( $\mathrm{P}<0.05$; Fig. 7).

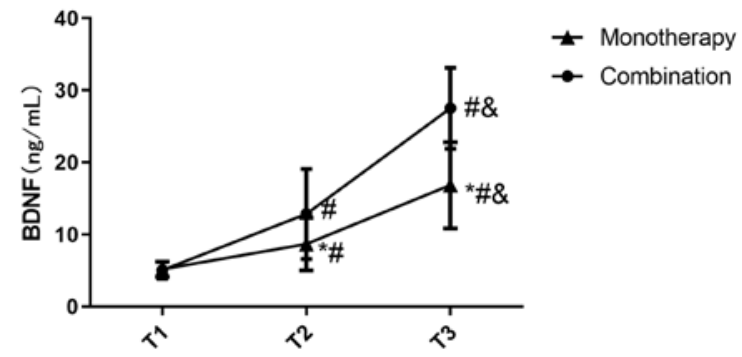

Figure 7. Comparison of changes in BDNF levels between the combination and monotherapy groups during treatment as measured at three different time points. BDNF levels in the monotherapy group was significantly lower compared with that in the combination group at T2 and T3. In both groups, BDNF levels were higher at T3 compared with $\mathrm{T} 2$, which were in turn higher compared with $\mathrm{T} 1 .{ }^{*} \mathrm{P}<0.05$ vs. combination; ${ }^{\text {}} \mathrm{P}<0.05$ vs. corresponding value at $\mathrm{T} 1$ and ${ }^{\&} \mathrm{P}<0.05$ vs. corresponding value at $\mathrm{T} 2$. BDNF, brain-derived neurotrophic factor; $\mathrm{T} 1$, before treatment; $\mathrm{T} 2$, one week after treatment; T3, two weeks after treatment.

\section{Discussion}

PM is an infectious disease caused by purulent bacterial infection in the central nervous system (CNS). Specifically, toxins produced by the bacteria can induce aberrant inflammatory responses in the arachnoid and pia mater. If not treated immediately, the bacterial toxins can spread to the brain parenchyma and spinal cord, at which point more intensive treatments would be required with a guarded prognosis (18). The main pathogens responsible for infant PM are gram-negative bacteria and Staphylococcus aureus (19). PM is frequently accompanied with fibrin exudation and neutrophil infiltration, resulting in susceptibility to inflammatory small vessel embolism, focal cerebral infarction and encephalorrhagia (20). On clinical suspicion of PM, an empirical antibacterial therapeutic strategy is first adopted, where targeted antibiotic treatment is initiated as soon as the presence of the pathogen is confirmed (21).

Among the antibacterial pharmacological agents currently applied for PM, ceftriaxone sodium is the most frequently used. 
Mechanistically, ceftriaxone sodium operates by increasing the expression of intracellular glutamate transporters to reduce the levels of excitatory glutamate and enhance neuroprotection, reducing the risk of brain tissue damage (22). However, with the rise in drug-resistant bacterial strains, the use of ceftriaxone alone has not achieved desirable outcomes for the treatment of PM. In such cases, administration of dexamethasone, a commonly used glucocorticoid, is applied. In addition to the suppression of inflammation by mainly inhibiting macrophage activity, dexamethasone has also been previously demonstrated to reduce intracranial pressure and cerebral edema (23).

BDNF is a vital neurotrophic factor in CNS that serves a role in promoting neuronal survival and differentiation in the human body (24). For the treatment of PM, BDNF application can significantly reduce neuronal damage in the hippocampus, which may accelerate rehabilitation and improve prognosis. However, insufficient studies regarding the association between PM and BDNF exist. By comparing the efficacy of ceftriaxone sodium combined with dexamethasone to ceftriaxone sodium alone in patients with PM and monitoring changes in BDNF levels, the present study demonstrated a potential clinical role of ceftriaxone sodium combined with dexamethasone for infant PM treatment.

The results from the present study indicated that the effective treatment rate of the combination group was superior to that of the monotherapy group. The recovery time of body temperature, $\mathrm{PB}$ and $\mathrm{CF}$ WBC counts in the combination group was shorter compared with that of the monotherapy group, suggesting that ceftriaxone sodium combined with dexamethasone in PM was more effective compared with ceftriaxone alone. It could be hypothesized that these observations may be due to the anti-inflammatory properties of dexamethasone or the expansion of the ceftriaxone antibacterial spectrum. The use of ceftriaxone sodium alone has poor antibacterial effect and is likely to cause resistance in children. In children with PM, the metabolic function of central nervous system is abnormal due to the influence of bacterial toxins, which has an impact on glucose transporters and blood circulation fluidity (25).

There was no significant difference in the incidence of adverse reactions between the two treatment groups, suggesting that both therapeutic strategies are safe and worthy of clinical promotion. Some bacteria are able to convert glucose in the CSF to lactic acid (26), where the resultant inflammatory response can increase the level of antibodies in the CSF of patients with PM (27). Compared with the monotherapy group, CSF sugar concentrations were higher in the combination group, whilst the CSF protein concentrations were lower, suggesting that ceftriaxone sodium combined with dexamethasone was more effective in improving CSF function and CNS metabolism.

Dexamethasone inhibits the release of chemokines by reducing the stimulation of the inflammatory cells such as monocytes (28). As a result, damage to the neurovascular system is greatly reduced. In addition, dexamethasone contributed to the stabilization of the vascular endothelial structure and was of great significance to the protection of neurons and blood vessels (29). This was speculated to be a reason for the higher BDNF levels observed in the combination group compared with the monotherapy group in the present study.
Previous studies have demonstrated that BDNF can regulate the expression of cortical neurons and hippocampal neurons through the MARK/ERK pathway $(30,31)$. Although it could be speculated that dexamethasone inhibited the MAPK/ERK pathway, further research is required to explore the intracellular mechanism of BDNF action.

Small sample size was a limitation of this study. Further research and discussion are needed to clarify the mechanism of the effects of the combination of ceftriaxone sodium and dexamethasone on BDNF levels in infant PM. A longer follow-up of patients should be performed in a future study.

In conclusion, the effects of ceftriaxone combined with dexamethasone for the treatment of infant PM was found to be superior compared with ceftriaxone alone. In addition, ceftriaxone combined with dexamethasone improved the effective treatment rate and rehabilitation of patients with PM and also improved the BDNF levels in patients.

\section{Acknowledgements}

Not applicable.

\section{Funding}

No funding was received.

\section{Availability of data and materials}

The datasets used and/or analyzed during the current study are available from the corresponding author on reasonable request.

\section{Authors' contributions}

WYZ and WZ conceived the study and designed the experiments, contributed to the data collection, performed the data analyses, and interpreted the results. WYZ drafted the manuscript. ZW contributed to the critical revision of the article. All authors read and approved the final draft of the manuscript.

\section{Ethics approval and consent to participate}

The present study was approved by the Ethics Committee of Yongchuan Hospital of Chongqing Medical University (Chongqing, China), and informed consent was obtained from all the parents of the subjects.

\section{Patient consent for publication}

Not applicable.

\section{Competing interests}

The authors declare that they have no competing interests.

\section{References}

1. Qian Y, Wong CC, Lai SC, Lin ZH, Zheng WL, Zhao H, Pan KH, Chen SJ and Si JM: Klebsiella pneumoniae invasive liver abscess syndrome with purulent meningitis and septic shock: A case from mainland China. World J Gastroenterol 22: 2861, 2016. 
2. He Z, Li X and Jiang L: Clinical analysis on 430 cases of infantile purulent meningitis. Springerplus 5: 1994, 2016.

3. Agossou J, Adédémy JD, Noudamadjo A, Houessou MRM, Tsawlassou P, Assogba R, Sagbo GG, Lalya HF, Alao MJ, Bankolé $\mathrm{H}$, et al: Serotypes of bacteria encountered in childhood purulent meningitis in children in Parakou (Benin) in 2011. Open J Pediat 6: 109, 2016.

4. Du H, Liu E, Xu C, Zhao S, Xiang H and Li Z: Prognostic value of funisitis and/or chorionic vasculitis compared to histologic chorioamnionitis in full-term infants. The J Matern Fetal Neonatal Med 30: 169-173, 2017.

5. Liu C and Zhao D: Correlation between CD64 and PCT levels in cerebrospinal fluid and degree of hearing impairment sequelae in neonates with purulent meningitis. Exp Ther Med 14: 5997-6001, 2017.

6. Lan SY, Lin JJ, Hsia SH, Wang HS, Chiu CH and Lin KL; CHEESE Study Group: Analysis of fulminant cerebral edema in acute pediatric encephalitis. Pediatr Neonatol 57: 402-407, 2016.

7. Ai J, Xie Z, Liu G, Chen Z, Yang Y, Li Y, Chen J, Zheng G and Shen K: Etiology and prognosis of acute viral encephalitis and meningitis in Chinese children: A multicentre prospective study. BMC Infect Dis 17: 494, 2017.

8. Yimer EM, Hishe HZ and Tuem KB: Repurposing of the $\beta$-lactam antibiotic, ceftriaxone for neurological disorders: A review. Front Neurosci 13: 236, 2019

9. Xu W, Yin M, Huo MC, Yan JL, Yang Y and Liu CF: Changes in blood $\mathrm{CD} 4{ }^{+} \mathrm{CD} 25^{+}$regulatory $\mathrm{T}$ cells in children with severe purulent meningitis. Zhongguo Dang Dai Er Ke Za Zhi 18: 821-825, 2016 (In Chinese).

10. Rahman M, Khan MA, Abdul Rub M, Hoque MA and Asiri AM: Investigation of the effect of various additives on the clouding behavior and thermodynamics of polyoxyethylene (20) sorbitan monooleate in absence and presence of ceftriaxone sodium trihydrate drug. J Chem Eng Data 62: 1464-1474, 2017.

11. Rahman M, Khan MA, Rub MA and Hoque MA: Effect of temperature and salts on the interaction of cetyltrimethylammonium bromide with ceftriaxone sodium trihydrate drug. J Mol Liquids 223: 716-724, 2016

12. Patel N, Lalwani D, Gollmer S, Injeti E, Sari Y and Nesamony J: Development and evaluation of a calcium alginate based oral ceftriaxone sodium formulation. Prog Biomater 5: 117-133, 2016

13. Guo X, Wan J, Yu X and Lin Y: Study on preparation of $\mathrm{SnO}_{2}-\mathrm{TiO}_{2} / \mathrm{Nano}$-graphite composite anode and electro-catalytic degradation of ceftriaxone sodium. Chemosphere 164: 421-429, 2016.

14. Fu Y, Jing J, Ren $\mathrm{T}$ and Zhao H: Intratympanic dexamethasone for managing pregnant women with sudden hearing loss. J Int Med Res 47: 377-382, 2019.

15. Dileep A, Khan NB and Sheikh SS: Comparing neonatal respiratory morbidity in neonates delivered at term by elective Caesarean section with and without dexamethasone Retrospective cohort study. J Pak Med Assoc 65: 607-611, 2015.

16. Tange M, Yoshida M, Nakai $Y$ and Uchida T: The role of an impurity in ceftriaxone sodium preparation for injection in determining compatibility with calcium-containing solutions. Chem Pharm Bull (Tokyo) 64: 207-214, 2016.

17. Di Cicco M, Bellino EM, Marabotti A, Luti L, Peroni DG and Baroncelli GI: Acute dacryocystitis with giant lacrimal abscess: A case report. Ital J Pediatr 46: 15, 2020.
18. Guo LY, Zhang ZX, Wang X, Zhang PP, Shi W, Yao KH, Liu LL, Liu G and Yang YH: Clinical and pathogenic analysis of 507 children with bacterial meningitis in Beijing, 2010-2014. Int J Infect Dis 50: 38-43, 2016.

19. Rodriguez WJ, Ross S, Khan WN and Goldenberg R: Clinical and laboratory evaluation of cefamandole in infants and children. J Infect Dis 137: S150-S154, 1978.

20. Ekhtiyari E, Barzegar M, Mehdizadeh A, Shaaker M, Ghodoosifar S, Abhari A and Darabi M: Differential fatty acid analysis of cerebrospinal fluid in infants and young children with suspected meningitis. Child's Nerv Sys 33: 111-117, 2017.

21. Kępa L, Oczko-Grzesik B, Stolarz W and Boron-Kaczmarska A: Cerebrospinal fluid ferritin concentration in patients with purulent, bacterial meningitis-own observations. Przegl Epidemiol 70: 593-603, 2016 (In English, Polish).

22. Sharma VD, Singla A, Chaudhary M and Taneja M: Population pharmacokinetics of fixed dose combination of ceftriaxone and sulbactam in healthy and infected subjects. AAPS PharmSciTech 17: 1192-1203, 2016.

23. Dimopoulos MA, Moreau P, Palumbo A, Joshua D, Pour L, Hájek R, Facon T, Ludwig H, Oriol A, Goldschmidt H, et al: Carfilzomib and dexamethasone versus bortezomib and dexamethasone for patients with relapsed or refractory multiple myeloma (ENDEAVOR): A randomised, phase 3, open-label, multicentre study. Lancet Oncol 17: 27-38, 2016.

24. Jha A, Dwivedi NC, Verma SK and Chaurasia AK: Role of cerebrospinal fluid, creatine kinase and lactate dehydrogenase enzyme levels in diagnostic and prognostic evaluation of tubercular and pyogenic meningitis. Int J Adv Med 4: 824-829, 2017.

25. Scoppetta TLPD, da Rocha AJ and Nunes RH: Meningitis, empyema, and brain abscess in adults. In: Editors. Critical Findings in Neuroradiology. Springer 141-154, 2016.

26. Ahmed R: Gestational dexamethasone alters fetal neuroendocrine axis. Toxicol Lett 258: 46-54, 2016.

27. Panackal AA, Chittboina P, Marr KA, Bielekova B and Williamson PR: Dexamethasone in cryptococcal meningitis. N Engl J Med 375: 188, 2016.

28. Miao YL, He P, Zhang WX, Zhang WZ, Feng M and Ni Y: Anti-inflammatory mechanism of Crepis crocea based on NF- $\kappa B$ signaling pathway and $\sim 1 \mathrm{H}-\mathrm{NMR}$ metabonomics. Zhongguo Zhong Yao Za Zhi 45: 946-954, 2020 (In Chinese).

29. Barna L, Walter FR, Harazin A, Bocsik A, Kincses A, Tubak V, Jósvay K, Zvara Á, Campos-Bedolla P and Deli MA: Simvastatin, edaravone and dexamethasone protect against kainate-induced brain endothelial cell damage. Fluids Barriers 17: 5, 2020.

30. Zhang JC, Yao W and Hashimoto K: Brain-derived neurotrophic factor(BDNF)-TrkB signaling in inflammation-related depression and potential therapeutic targets. Curr Neuropharmacol 14: 721-731, 2016.

31. El Morsy EM and Mae A: Protective effects of lycopene on hippocampal neurotoxicity and memory impairment induced by bisphenol A in rats. Hum Exp Toxicol: 960327120909882, 2020.

This work is licensed under a Creative Commons Attribution-NonCommercial-NoDerivatives 4.0 International (CC BY-NC-ND 4.0) License. 